\title{
Evaluation of effects of rumen fluid in combination with probiotic preparations and vanillin on the luminescence of a recombinant strain E. coli
}

\author{
Il'shat Karimov ${ }^{1}$, Kristina Kondrashova ${ }^{2}$, Galimzhan Duskaev² and Olga Kvan² \\ ${ }^{1}$ Orenburg state university, 460018, Orenburg, Russia \\ ${ }^{2}$ Federal Research Centre of Biological Systems and Agro-technologies of the Russian Academy of Sciences, 9th Yanvarya St., 29, \\ 460000, Orenburg, Russia
}

\begin{abstract}
A way to assess the metabolic state of bacteria of rumen microflora cells is the registration of glow kinetics including recombinant strains, which is a reflection of stress states developing in the cell. The experiment evaluated the effect of rumen fluid in combination with probiotic strains and vanillin on the luminescence of a recombinant strain Escherichia coli MG1655 and digestibility of feed. The "in vitro" method with the rumen simulation technique (Rusitec) was used to determine the digestibility of the dry substance of feed. Using the initial sample, the glow level at the 30th minute was recorded at $3,149 \pm 145 \mathrm{RLU}$, which is $32 \%$ of the control level. In the presence of rumen fluid (at the concentration of $6.25 \%$ ), there was observed an improved response by E.coli against Saccharomyces boulardii's background (by 44\%). The use of vanillin in rumen fluid increases the glow level of bacterial cells in the range of concentrations up to $50 \%$, and in combination with probiotic strains, in the range of $25-50 \%$. In vitro conditions against the background of rumen fluid showed that vanillin in combination with probiotic strains Bifidobacterium longum and Bifidobacterium adolescentis / Lactobacillus acidophilus contributes to an increase in the digestibility of the dry substance of feed.
\end{abstract}

\section{Introduction}

The work of the digestive system of cattle directly determines the rate of increase in animal biomass [1]. Changing the pattern of feeding also determines the characteristics of the microbial community [2], which leads to a change in the metabolites present in the rumen [3]. Such conditions have the potential to increase the efficiency of microorganisms [4] or to form stress states in the bacterial microflora [5]. Unsaturated fatty acids, which comprise a significant proportion of rumen fluid metabolites [6], can disrupt the integrity of membranes, alter the cell morphology, and reduce its vitality leading to activation of a number of stress genes including global regulators MarA, Rob, SoxS [7]. In addition to the optimization of the feed substrate, there are various additives that are used to feed animals to improve or optimize digestion. To this end, there are used probiotic microorganisms that have a beneficial effect on the digestibility of nutrients that provide protection against pathogenic microflora or populate free niches in this microbiome. In addition, plant extracts $[8,9]$ or other molecular compositions may be used to improve biomass growth. A way to assess the metabolic state of bacteria of rumen microflora cells is the registration of glow kinetics including recombinant strains, which is a reflection of stress states developing in the cell.

In this regard, the purpose of this work was to evaluate the biological activity of rumen fluid in combination with probiotic strains and vanillin on the luminescence of a recombinant strain E. coli MG1655 and the digestibility of feed.

\section{Materials and methods}

As sensory cells, there was used the Escherichia coli K12 MG1655 culture transformed by the recombinant plasmid $p X e n 7$, which carries luxCDABE genes of the natural luminescent bacteria Photorhabdus luminescens ZM1 under the control of a lactose-based promoter, as well as genes of resistance to ampicillin (selective factor). The bacteria were grown for 24 hours at $37 \mathrm{C}$ on LBagar (Sigma-Aldrich, USA) in the presence of 100 micrograms $/ \mathrm{ml}$ of ampicillin. Just before the measurement, the biomass was washed away with sterile LB-broth, and then it was standardized to optical density of 0.5 relative units at $540 \mathrm{~nm}$ taking similar measurements in the basins of transparent tablets at the photometer "StatFax 303" (Awareness, USA).

Probiotic strains of Lactobacillus fermentum 90T-C4 (at least $\left.2 \times 10^{9} \mathrm{CFU}\right)$, Saccharomyces boulardii $(250 \mathrm{mg})$, Bifidobacterium longum (50 million CFU), and Bifidobacterium adolescentis / Lactobacillus acidophilus (80.0 million CFU / 1.0 million CFU per $1 \mathrm{~g}$ ) were used for the study.

As a growth factor, chemically synthesized vanillin (Sigma-Aldrich, USA), which is characterized by

\footnotetext{
* Corresponding author: kwan111@yandex.ru
} 
activity in the quorum-dependent bacteria systems [10], was applied.

There was preliminarily formed a mixture of $1000 \mu \mathrm{l}$ of rumen fluid, $100 \mu \mathrm{l}$ of a probiotic strain, and $100 \mu \mathrm{l}$ of vanillin (or saline solution in control samples), then it was incubated for an hour at $37 \mathrm{C}$. Further research was carried out in 96-basin tablets, where the test subjects were prepared by double diluting in saline solution of 50 $\mu \mathrm{l}$, and then $150 \mu \mathrm{l}$ of the prepared suspension of the luminescent biosensor Escherichia coli K12 MG1655 was added and the glow kinetics got evaluated for 60 minutes on the tablet luminometer Tecan (Austria).

The "in vitro" method with the rumen simulation technique (Rusitec) was used to determine the digestibility of the dry substance of feed.

\section{Results and discussion}

The kinetics of the E.coli MG1655 pXen7 glow depended heavily on the concentration of rumen fluid. Using the initial sample, the glow level at the $30^{\text {th }}$ minute was recorded at $3,149 \pm 145 \mathrm{RLU}$, which is $32 \%$ of the control level (Figure 1). As previously described [11], this effect is primarily associated with acute toxicity, which is confirmed by the four-time difference of luminescence $(577 \pm 36 \mathrm{RLU}$ in the experiment vs. $2232 \pm 132$ RLU in the control) at the first second of contact. Further two-fold dilution of rumen fluid led to the expected reduction of the toxic action with changing the shape of the glow kinetic curve. The level of glow in the assessment of acute toxicity in the test sample was observed significantly indistinguishable at the rumen fluid concentration of 12.5 percent or less, and at the last minute of the measurement - only at 3.125 percent or less. This indicates the presence of a group of factors acting prolongedly and leading to a decrease in metabolic bacterial activity. In particular, unsaturated fatty acids as the prevailing metabolite of rumen fluid [3] may be one of these factors. By interacting with fluorescent bacteria, they can reduce luminosity along the way of competitive interaction with luciferase as a substrate for the active center of this enzyme [12].

Introducing the system of probiotic preparations did not directly affect the luminescence of the bacterial biosensor, which was reflected in the significantly indistinguishable from the control of glow indicators. However, the presence of rumen fluid at a concentration of 6.25 percent increased the response of E.coli MG1655 pXen 7 : by $44 \%$ in the case of Saccharomyces boulardii while the remaining strains had a similar effect in the range of 21-24 percent (Figure 2). It is worth noting that at the threshold rumen fluid concentration of $12.5 \%$ lying on the line of the maximum angle of the glow of the biosensor, there was no effect from probiotic cultures recorded. At concentrations of $25 \%$ and $50 \%$, the luminescence of E.coli MG1655 pXen7 was consistently higher than that of control using any type of probiotic. This phenomenon is explained by binding the active components of rumen fluid by the cells of the probiotic culture that acts as an additional target for the action of the contents of the biological fluid in this case.
The direct effect of vanillin on the luminescent biosensor E.coli MG1655 pXen7 was not characterized by significant differences from the control level $(10744 \pm 592$ vs. $11616 \pm 394)$. However, when vanillin was applied as an additive introduced in rumen fluid, there was an increase in the glow of bacterial cells, and this amplifying effect was observed in the concentration range of up to $50 \%$ of this biological fluid (Figure 3 ).

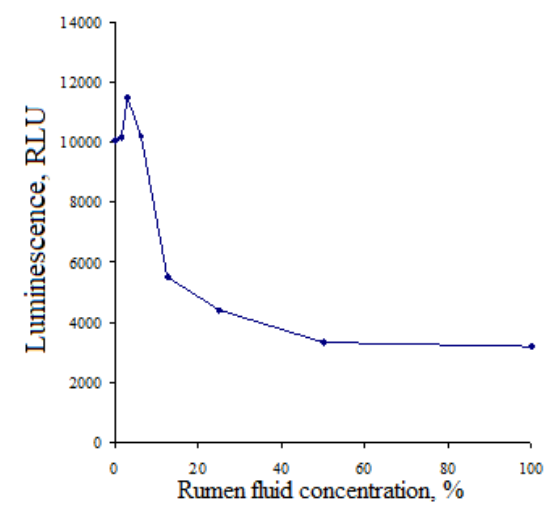

Fig. 1 Biosensor Escherichia coli MG1655 pXen7 glow dependency on the concentration of rumen fluid (at the $30^{\text {th }}$ minute)

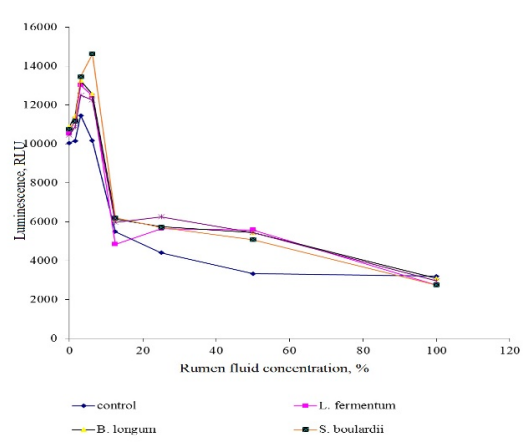

Fig. 2 Biosensor Escherichia coli MG1655 pXen7 glow dependency on the concentration of rumen fluid in the presence of probiotics

The use of the complex "a probiotic + vanillin" increases the glow of bacterial cells, and this amplifying effect was observed in the concentration range of $25-50 \%$ of this biological fluid (Figure 4).

At the same time, the effect was almost absent against the background of the rumen fluid concentrations of 100 and $12.5 \%$. 


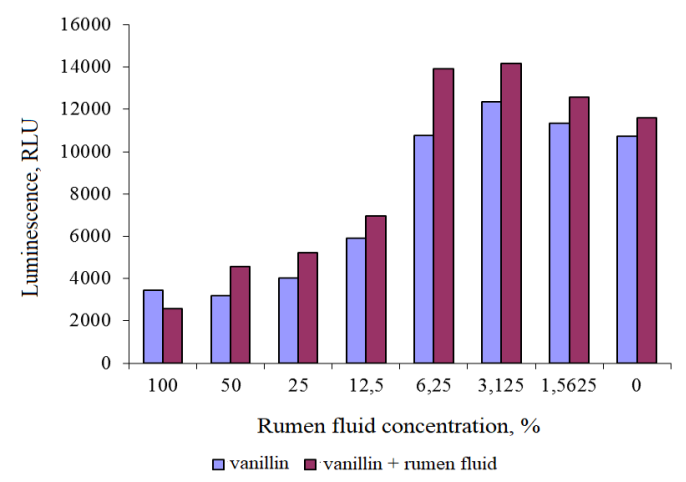

Fig. 3 Biosensor Escherichia coli MG1655 pXen7 glow dependency on the concentration of rumen fluid in the presence of probiotics

The effect of vanillin on the nature of the toxic effect of rumen fluid on the biosensor Escherichia coli MG1655 pXen 7

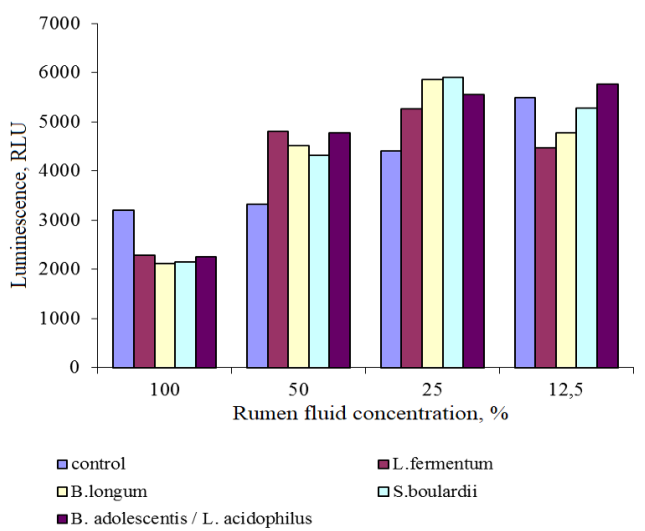

Fig. 4 Effects of probiotic strains and vanillin on the nature of the toxic effect of rumen fluid on the biosensor Escherichia coli MG1655 $p$ Xen 7

The results of the in vitro wheat digestibility analysis against the background of rumen fluid showed that vanillin combined with probiotic strains Bifidobacterium longum and Bifidobacterium adolescentis / Lactobacillus acidophilus contributes to its increase, which may be associated with changes in the microbiome of the rumen and the ability to control bacteria by inactivation of lactones $[13,14]$.

Table 1. Digestion of wheat dry matter in vitro against the background of rumen fluid, $\%$

\begin{tabular}{|c|c|c|c|}
\hline Group & Index & SEM & P-value \\
\hline Control & 42.61 & 6.50 & - \\
\hline Vanillin & 32.64 & 1.78 & NS \\
\hline $\begin{array}{c}\text { Saccharomyces } \\
\text { boulardii }\end{array}$ & 32.20 & 3.34 & NS \\
\hline $\begin{array}{c}\text { Saccharomyces } \\
\text { boulardii + vanilin }\end{array}$ & 35.67 & 5.21 & NS \\
\hline $\begin{array}{c}\text { Lactobacillus } \\
\text { fermentum }\end{array}$ & 34.0 & 5.12 & NS \\
\hline $\begin{array}{c}\text { Lactobacillus } \\
\text { fermentum + vanilin }\end{array}$ & 33.46 & 4.00 & NS \\
\hline Bifidobacterium longum & $22.96^{\mathrm{a}}$ & 4.53 & $*$ \\
\hline
\end{tabular}

\begin{tabular}{|c|c|c|c|}
\hline $\begin{array}{c}\text { Bifidobacterium longum } \\
\text { + vanilin }\end{array}$ & 40.8 & 2.18 & NS \\
\hline $\begin{array}{c}\text { Bifidobacterium } \\
\text { adolescentis / } \\
\text { Laktobacillus } \\
\text { acidophilus }\end{array}$ & $27.68^{\mathrm{b}}$ & 5.41 & $*$ \\
\hline $\begin{array}{c}\text { Bifidobacterium } \\
\text { adolescentis / } \\
\text { Laktobacillus } \\
\text { acidophilus + vanilin }\end{array}$ & 34.64 & 5.63 & $\mathrm{NS}$ \\
\hline
\end{tabular}

$\mathrm{a}, \mathrm{b}-$ values in rows with different letters differ significantly $(\mathrm{P}<0.05)$.

SEM - standard error of the mean.

Thus, vanillin in combination with probiotic strains in the range of $25-50 \%$ of rumen fluid does not affect its biological activity, at the same time, Bifidobacterium longum and Bifidobacterium adolescentis / Lactobacillus acidophilus contribute to an increase in the digestibility of the dry substance feed.

\section{Acknowledgments}

The studies were performed in accordance with the plan of research works of Federal Research Centre of Biological Systems and Agrotechnologies of the Russian Academy of Sciences 0526-2019-0005.

\section{References}

1. Herd, R. M., Oddy, V. H. \& Richardson, E. C. (2004). Biological basis for variation in residual feed intake in beef cattle. 1. Review of potential mechanisms. Aust. J. Exp. Agr. 44, 423

2. Myer, P. R. et al. Rumen microbiome from steers differing in feed efficiency. PloS one 10, e0129174 (2015).

3. Artegoitia V.M., Foote A.P., Lewis R.M., Freetly H.C. (2017). Rumen Fluid Metabolomics Analysis Associated with Feed Efficiency on Crossbred Steers // Scientific Reports volume 7, Article number: 2864

4. Indugu, N., Vecchiarelli, B., Baker, L. D., Ferguson, J. D., Vanamala, J., \& Pitta, D. W. (2017). Comparison of rumen bacterial communities in dairy herds of different production. BMC microbiology, 17(1), 190.

5. Romero-Pérez, G. A., Ominski, K. H., McAllister, T. A., \& Krause, D. O. (2011). Effect of environmental factors and influence of rumen and hindgut biogeography on bacterial communities in steers. Applied and environmental microbiology, 77(1), 258-268. doi:10.1128/AEM.01289-09

6. Toral P.G., Monahan F.J., Hervás G., Frutos P., Moloney A.P. (2018). Review: Modulating ruminal lipid metabolism to improve the fatty acid composition of meat and milk. Challenges and opportunities // Animal. Dec;12(s2):s272-s281. doi: $10.1017 / \mathrm{S} 1751731118001994$. 
7. Lennen R. M., Kruziki M. A., Kumar K., Zinkel R. A., Burnum K. E., Lipton M. S., Hoover S. W., Ranatunga D. R., Wittkopp T. M., Marner II W. D., Pfleger B. F. (2011) Membrane Stresses Induced by Overproduction of Free Fatty Acids in Escherichia coli // Applied and Environmental Microbiology Nov, $77 \quad$ (22) 8114-8128; $\quad$ DOI: 10.1128/AEM.05421-11

8. Ge C. R., Jia J. J., Gao S. Z., Huang Q. C., Li F. D., Jois M. (2007). Feeding a natural plant extract affects growth performance in beef cattle // J. Anim. Feed Sci.;16(Suppl. 2):586-591

9. Hundal J. S., Singh I., Wadhwa M., Singh C., Uppal C., Kaur G. Effect of Punica granatum and Tecomella undulata supplementation on nutrient utilization, enteric methane emission and growth performance of Murrah male buffaloes. J. Anim. Feed Sci. 2019;28(2):110-119.

10. Karimov I., Duskaev G., Inchagova K., Kartabaeva M. Inhibition of bacterial Quorum sensing by the ruminal fluid of cattle. International Journal of GEOMATE, Dec., 2017, Vol. 13, Issue 40, pp.88-92.

11. Logachev K., Karimov I., Duskaev G., Frolov A., Tulebaev S. and Zav'yalov O. 2015. Study of Intercellular Interaction of Ruminal Microorganisms of Beef Cattle. Asian Journal of Animal Sciences, 9: 248-253.

12. Deryabin D.G., Karimov I.F. Characteristics of the response of natural and recombinant luminescent microorganisms in the presence of $\mathrm{Fe} 2+$ ions // Applied Biochemistry and Microbiology. 2010. T. 46. № 1. C. 28-32.

13. Duskaev G., Karimov I., Levakhin G., Nurzhanov B., Rysaev A. and H. Dusaeva. Ecology of ruminal microorganisms under the influence of quercus cortex extract. International Journal of GEOMATE, March, 2019 Vol.16, Is-sue 55, pp. 59 - 66.

14. Karimov I., Duskaev G., Inchagova K., Kartabaeva M. Inhibition of bacte-rial Quorum sensing by the ruminal fluid of cattle. International Journal of GEOMATE, Dec., 2017, Vol. 13, Issue 40, pp.88-92. 